\title{
Pengendalian Otomatis Cooling Water System pada Proses Pendinginan Turbin Gas
}

\author{
li Munadhif1), Noorman Rinato2), Muhammad Afiqi ${ }^{3)}$ \\ ${ }^{1,2,3)}$ Program Studi Teknik Otomasi Politeknik Perkapalan Negeri Surabaya \\ 1)iimunadhif.its@gmail.com, ${ }^{2}$ noorman.rinanto@gmail.com, ${ }^{3}$ fiqiotomasi@gmail.co.id
}

DOI: http://dx.doi.org/10.21107/rekayasa.v12i1.4389

\begin{abstract}
ABSTRAK
Di dalam pembangkit listrik tenaga gas, terdapat proses pendinginan turbin gas yang disebut Cooling water system (CWS). Sistem ini berfungsi mendinginkan minyak pelumas pendingin turbin yang saat suhu tinggi dapat menyebabkan shut down pada pembangkit listrik. Proses pendinginannya yang manual menyebabkan sistem tersebut kurang optimal. Oleh karena itu, penelitian ini mengusulkan sebuah inovasi purwarupa CWS otomatis. Perangkat kendalinya terdiri dari dua sensor thermocouple, sebuah papan kendali arduino, pompa air, 18 buah kipas sebagai pendingin dan heater sebagai perangkat gangguan saat pengujian. Sistem ini dilengkapi perangkat antarmuka untuk memudahkan dalam mengendalikan dan memonitoring sistemnya. Terdapat dua mode pengendalian sistem, yaitu mode manual dan mode otomatis. Kipas dapat dinyalakan sesuai kebutuhan pada mode manual, sedangkan mode otomatis sistem pendingin menyalakan sejumlah kipas berdasarkan tingkat kenaikan suhu. Suhu $35^{\circ} \mathrm{C}$ dipilih sebagai setpoint pada sistem ini. Pengujian sistem menunjukkan bahwa semakin tinggi suhu inlet pada CWS, maka semakin lama waktu yang diperlukan untuk menstabilkan sistem.

Kata Kunci: cooling water system, turbin gas, pengendali otomatis, suhu, antarmuka, kipas.
\end{abstract}

\section{Automatic Control Cooling Water System for Gas Turbine Cooling Process}

\begin{abstract}
In the gas power plant, there is a cooling process of gas turbine called Cooling water system (CWS). It is used to cool the lube oil cooler which at the high temperatures will cause shut down of the plant. A manual cooling process on this system, induce its performance to be less than optimal. Therefore, this research proposes an innovation of prototype automatic control of CWS. This system consists of the two thermocouples, an Arduino board, the water pump, 18 fans for cooler actuator and a heater as an annoying system. An interface is implanted in this system to facilitate control and monitoring system. There is two modes of control, manual mode, and automatic mode. In manual mode, the operator can turn on the fan as they needed. The system turns on the number of fans according to the level of detected temperature in automatic. $35^{\circ} \mathrm{C}$ is set to be a setpoint value. The system testing shows that the higher value of inlet temperature in CWS, the longer it takes to reach the setpoint.
\end{abstract}

Keywords: cooling water system, gas turbine, automatic controller, temperature, interface, fan.

\section{PENDAHULUAN}

Dewasa ini teknologi semakin berkembang dan telah memberikan banyak manfaat di berbagai aspek, salah satunya adalah industri Pembangkit Listrik Tenaga Gas (PLTG) untuk menunjang kelangsungan hidup manusia. Pada PLTG, terdapat Cooling water system (CWS) pada pendinginan gas turbin. Sistem ini merupakan salah satu terpenting dalam PLTG. Sebelum start turning gas turbin, sistem pendingin mulai mendinginkan pada lube

\section{Article History:}

Received: Oktober 2018; Accepted: Januari 2019

ISSN: 2502-5325 (Online) Terakreditasi Peringkat 4 oleh

Kementerian Riset, Teknologi dan Pendidikan Tinggi (ARJUNA)

berdasarkan Keputusan Direktur Jenderal Penguatan Riset dan

Pengembangan Nomor: 21/E/KPT/2018 tanggal 9 Juli 2018 oil cooler dan bergerak menuju generator air pendingin. Lube oil cooler adalah suatu sistem pendingin pada gas turbin menggunakan minyak sekaligus sebagai pelumas. Dengan panasnya minyak yang dihasilkan maka sangat diperlukan sebuah pendingin lube oil cooler untuk gas turbin melalui pipa air yang dingin. Sistem pendingin ini menggunakan sistem proses penukaran panas yaitu heat exchanger, dimana fluida yang didinginkan adalah oli atau udara, sedangkan fluida yang mendinginkan adalah air. Pada

\section{Cite this as:}

Munadhif, I., Rinato, N., \& Afiqi, M. (2019). Pengendalian Otomatis Cooling Water System pada Proses Pendinginan Turbin Gas. Rekayasa, 12(1), 36-42. doi:http://dx.doi. org/10.21107/rekayasa.v12i1.4389

(C) 2019 Universitas Trunojoyo Madura 
kondisi operasional didapatkan bahwa suhu oli keluar dari lube oil cooler masih cukup tinggi. Hal ini dapat menyebabkan turbin gas shut down (Sumarno,2015). Suhu lube oil cooler yang tinggi otomatis akan didinginkan oleh CWS. Air pendingin pada CWS ini dilalui oleh pipa-pipa yang saling menghubungkan satu sama lain menuju masing masing lube oil cooler pada setiap gas turbin. Sistem pendingin air ini menggunakan kipas yang berputar. Input air pendingin yang akan didinginkan berkisar antara $60^{\circ} \mathrm{C}-75^{\circ} \mathrm{C}$ dan output air pendingin setelah didinginkan yaitu $\leq 35^{\circ} \mathrm{C}$. Jumlah kipas yang beroperasi harus dikendalikan sesuai dengan suhu lingkungan. Jika suhu dari CWS telah diketahui lebih dari $40^{\circ} \mathrm{C}$, operator akan menambah jumlah kipas yang berputar di CWS agar mencapai suhu $\leq 35^{\circ} \mathrm{C}$. Jika suhu dari CWS lebih rendah dari $35^{\circ} \mathrm{C}$, operator akan mematikan kipas agar dapat meminimalisasi pemakaian listrik. Jadi peningkatan sistem dalam proses pengendalian CWS merupakan hal yang penting di industri pembangkit listrik tenaga gas. Oleh karena itu diperlukan suatu alat pengendalian kipas agar dapat bekerja secara maksimal. Alat pendingin yang terdiri dari sensor thermocouple sebagai pendeteksi suhu, dan arduino sebagai pengendali, serta pompa, 18 kipas dan pemanas sebagai aktuator. Sistem ini dilengkapi interface untuk memudahkan dalam mengendalikan dan memonitoring. Terdapat dua mode pengendalian kipas, yaitu manual dan otomatis. Mode otomatis menerapkan pengendalian perhitungan level suhu untuk menyalakan jumlah kipas sesuai suhu yang terbaca oleh sensor agar mencapai setpoint.

\section{METODE PENELITIAN}

\section{Perancangan Sistem}

Gambar 1 menunjukkan diagram blok perancangan sistem. Pada diagram tersebut memiliki tiga bagian yaitu masukan berupa data dari dua sensor thermocouple. Proses berupa pengendali arduino dan keluaran berupa 18 kipas dan 2 pompa air serta heater. Sensor thermocouple 1 sebagai pendeteksi suhu pada inlet CWS, Sensor thermocouple 2 sebagai pendeteksi suhu outlet CWS. Perbedaan data dari sensor thermocouple tersebut akan diproses oleh arduino untuk menyalakan atau mematikan 18 kipas.

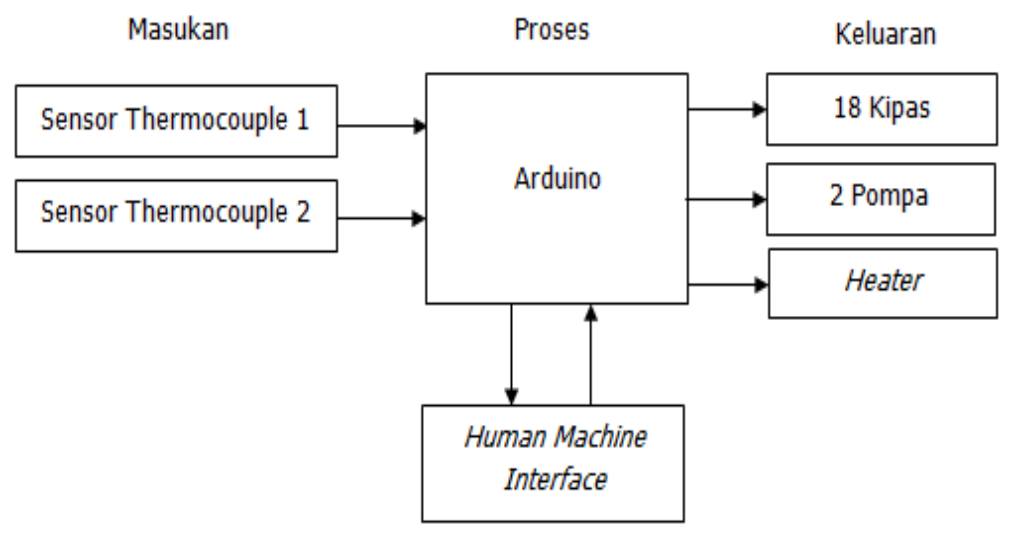

Gambar 1. Diagram blok perancangan sistem

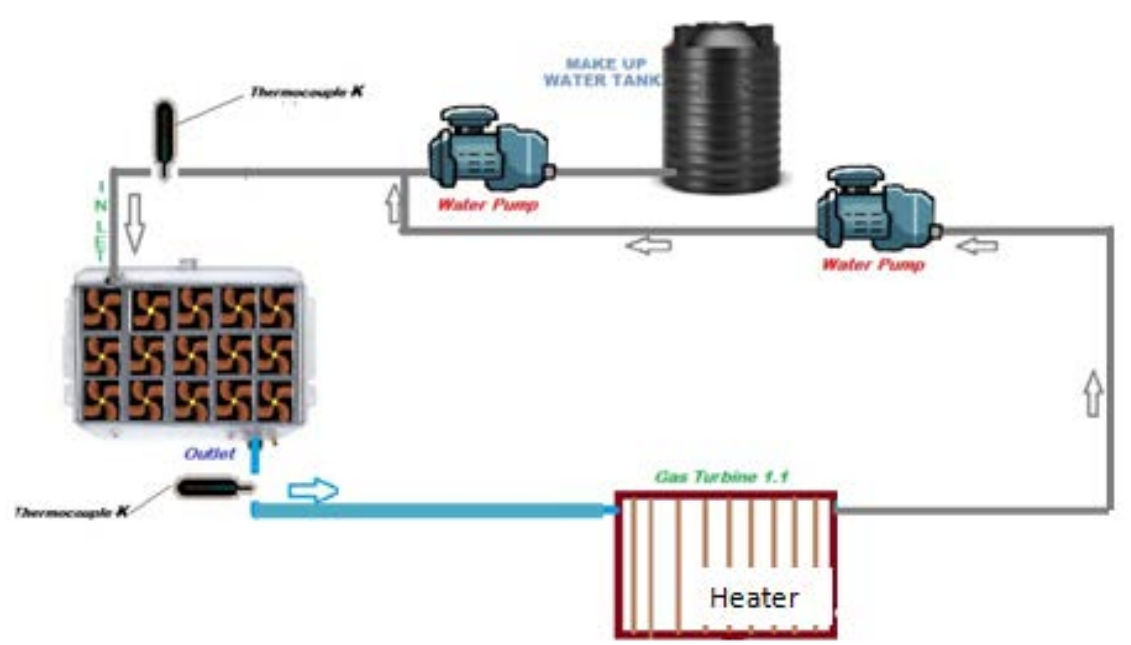

Gambar 2. Perancangan hardware 


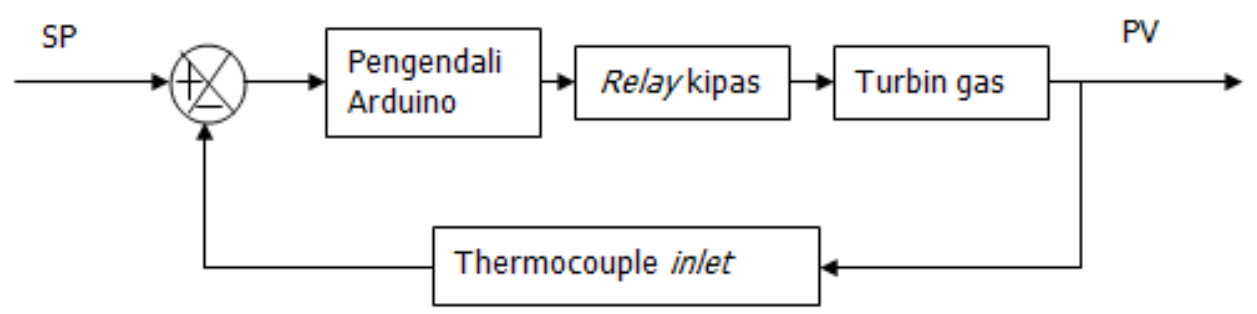

Gambar 3. Diagram blok pengendalian

Pompa 1 untuk memberikan air baru dari sumber air dan pompa 2 untuk mensirkulasikan air menuju CWS kembali. Sedangkan heater untuk memanaskan turbin gas sebagai asumsi bahwa gas turbin bekerja. Sistem ini dilengkapi human machine interface untuk memudahkan proses pengendalian dan monitoring bagi operator.

\section{Perancangan Hardware}

Perancangan hardware pada gambar 2 menjelaskan tentang beberapa komponen yang digunakan dan alur kerja sistem. Komponen hardware yang digunakan meliputi sebuah water tank, 2 buah pompa air, 18 kipas DC, 2 buah sensor thermocouple, dan sebuah heater sebagai asumsi pemanas turbinnya.

Alur kerja sistem pada penelitian ini adalah mula-mula pompa menyala dan mengalirkan air dari water tank melalui pipa kemudian melalui cubing-cubing radiator menuju pendingin CWS. Setpoint suhu untuk air pendingin gas turbin yaitu $\leq 35 \square$. Namun jumlah operasi kipas tergantung pada suhu lingkungan di area sistem pendingin tersebut. Jika suhu di atas 350 maka jumlah operasi kipas yang menyala harus bertambah banyak dari sebelumnya. Jika suhu di bawah 350 Jumlah operasi kipas yang menyala harus berhenti. 2 buah sensor termokopel mendeteksi suhu inlet dan outlet kemudian mengirim perbedaan data tersebut ke arduino untuk menggerakkan jumlah kipas yang sesuai suhu secara real time dengan cepat. Setelah air dapat didinginkan sesuai setpoint, maka air dapat diproses untuk mendinginkan gas turbin yang sedang beroperasi. Pompa 2 untuk mensirkulasikan air menuju sistem pendingin kembali.

\section{Perancangan Pengendalian}

Gambar 3 menunjukkan diagram blok pengendalian suhu, pengendali akan mengatur jumlah kipas yang menyala berdasarkan error. Error adalah selisih setpoint (SP) dengan present value (PV) dari pembacaan sensor pada inlet sistem. Jika suhu di sistem pendingin sesuai SP, maka pengendali menjaga kestabilan sistem. Pengendali menyalakan/ mematikan kipas melalui relay dari keluaran digital. Kipas yang dipakai adalah kipas 24 volt DC. Kipas membutuhkan supply tegangan 24 volt dari luar karena arduino hanya mampu mengelu- arkan tegangan 5 volt. Di dalam pengendali arduino terdapat logika pengendalian kipas dengan perhitungan level suhu.

Algoritma pengendalian CWS dengan menghitung level suhu yang diusulkan seperti ditunjukkan diagram alur pada gambar 4 .

Proses pengendalian seperti ditunjukkan pada gambar 4, diawali dengan inisialisasi nilai setpoint suhu $(S P)=350$, nilai batas atas suhu atau Maximum Value (MaxV) $=53$, nilai error $(E)=0$, dan jumlah fan yang aktif Fan $\mathrm{ON}=$ 0 . Kemudian dicek nilai suhu sekarang Present Value (PV) apakah masuk dalam range 350 < $\mathrm{PV}<53 \mathrm{C}$ ? Jika benar maka proses selanjutnya adalah dengan menghitung $\mathrm{E}$ dari selisih nilai PV dengan SP. Apabila nilai PV melebihi MaxV, maka nilai PV disamakan dengan nilai MaxV. Selanjutnya, nilai E dibulatkan untuk mendapatkan nilai bilangan bulat dan jumlah fan yang aktif Fan ON adalah sama dengan nilai E. Nilai ini kemudian dijadikan acuan untuk meng-aktifkan fan-fan yang terdapat dalam CWS.

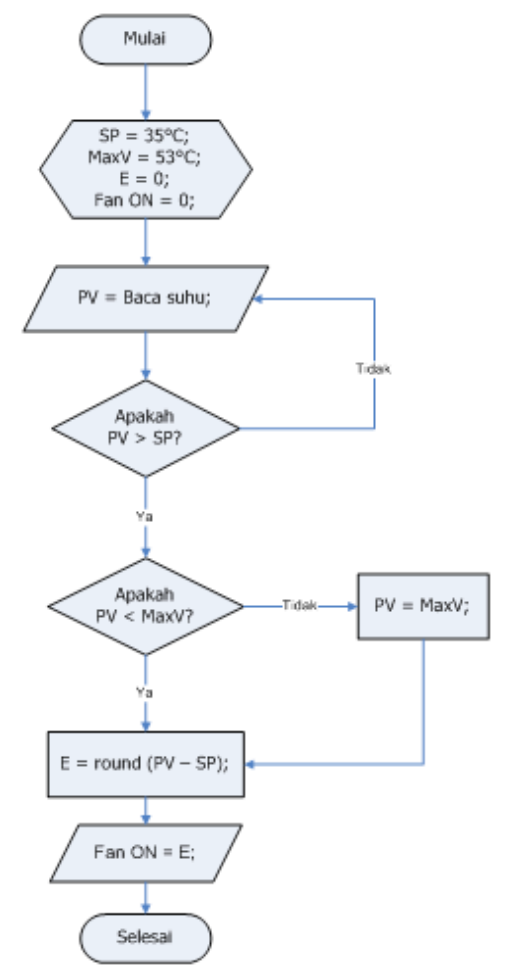

Gambar 4. Diagram alur pengendali CWS 


\section{Perancangan Thermocouple}

Gambar 5 adalah perancangan sensor thermocouple ke arduino. Sensor thermocouple K max 6675 adalah salah satu jenis sensor analog yang mengeluarkan tegangan analog sebagai representasi suhu untuk diteruskan ke arduino. Sensor ini mampu mendeteksi suhu $-200^{\circ} \mathrm{C}$ sampai $1200^{\circ} \mathrm{C}$ dengan resolusi pembacaan sensor sebesar $41 \mu \mathrm{V}$ setiap $1^{\circ} \mathrm{C}$. Sensor aktif membaca suhu karena mendapat sumber tegangan 5 volt dari arduino. Perubahan suhu yang dibaca oleh sensor dikonversi menjadi tegangan 0-5 volt dan dikirim ke arduino melalui pin analog 9 dan 10.

\section{Perancangan Kipas DC}

Kipas DC 24 volt diaktifkan oleh relay yang aktif atas perintah pengendali untuk mendinginkan air di CWS dan dibantu radiator untuk penukar panas. Kipas ini membutuhkan sumber tegangan $24 \mathrm{v}$ dan arus 0,07 ampere. Gambar 6 adalah perancangan kipas dari arduino. Kipas $24 \mathrm{v}$ mendapatkan sumber tegangan luar, arduino memerintahkan relay untuk mengubah posisi normaly open menjadi normaly close jika kipas ingin dinyalakan, dan juga sebaliknya jika ingin mematikan kipas maka relay tidak diaktifkan kembali

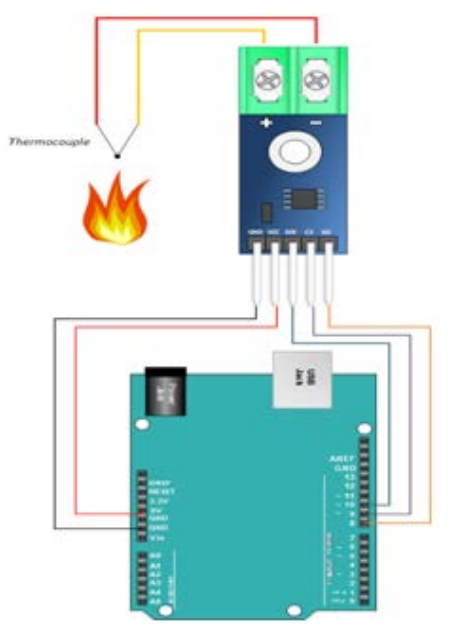

Gambar 5. Perancangan thermocouple ke arduino

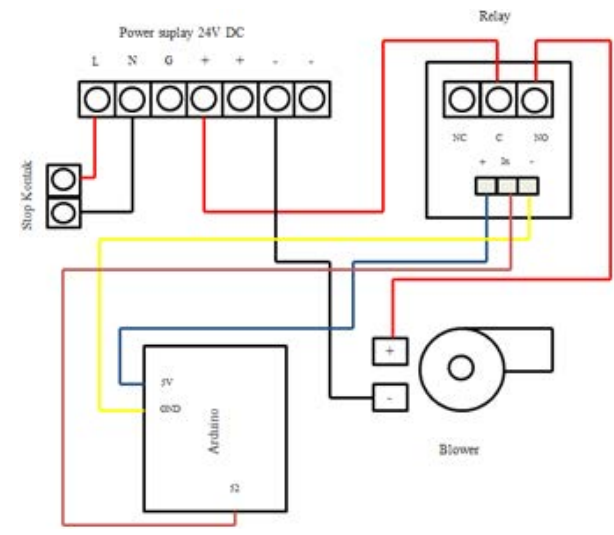

Gambar 6. Perancangan kipas 24V dari arduino

\section{Perancangan Heater dan Pompa}

Aktuator heater digunakan sebagai pemanas tangki gas turbin yang menandakan turbin beroperasi dengan suhu tinggi hingga $70 \mathrm{oC}$. Kemudian air hasil pemanasan dipompa kembali menuju sistem CWS untuk didinginkan. Heater ini juga diaktifkan oleh relay. Heater mendapatkan sumber tegangan luar $24 \mathrm{~V}$, arduino memerintahkan relay untuk mengubah posisi normaly open menjadi normaly close jika sistem diaktifkan. Heater ini terus diaktifkan selama proses berlangsung. Pada penelitian ini terdapat 2 pompa. Pompa 1 digunakan untuk menyalurkan air dari water tank dan pompa 2 untuk mensirkulasikan air dari turbin menuju CWS. Pompa air membutuhkan sumber tegangan 12 volt dan diaktifkan oleh arduino melalui driver saat proses dimulai. Gambar 7 adalah adalah perancangan heater dari arduino.

\section{Perancangan Software}

Perancangan software digunakan untuk pembuatan Human machine interface (HMI) agar memudahkan operator memantau dan mengendalikan sistem secara manual dan otomatis dan untuk mengaktifkan/mematikan sistem. Software yang digunakan adalah software visual studio 2013. Gambar 8 adalah perancangan HMI dengan visual studio 2013. Pada gambar 8 terdapat menu koneksi untuk menyambungkan software visual dengan hardware arduino. Menu monitoring suhu inlet dan outlet untuk mengetahui perubahan suhu. 18 Kipas dengan indikator gelap jika mati dan terang jika hidup. Menu tombol on off manual untuk mengoperasikan kipas secara manual dan arah pergerakan air dengan tanda panah berwarna biru putih. Sedangkan pipa merah adalah indikator air dalam keadaan panas

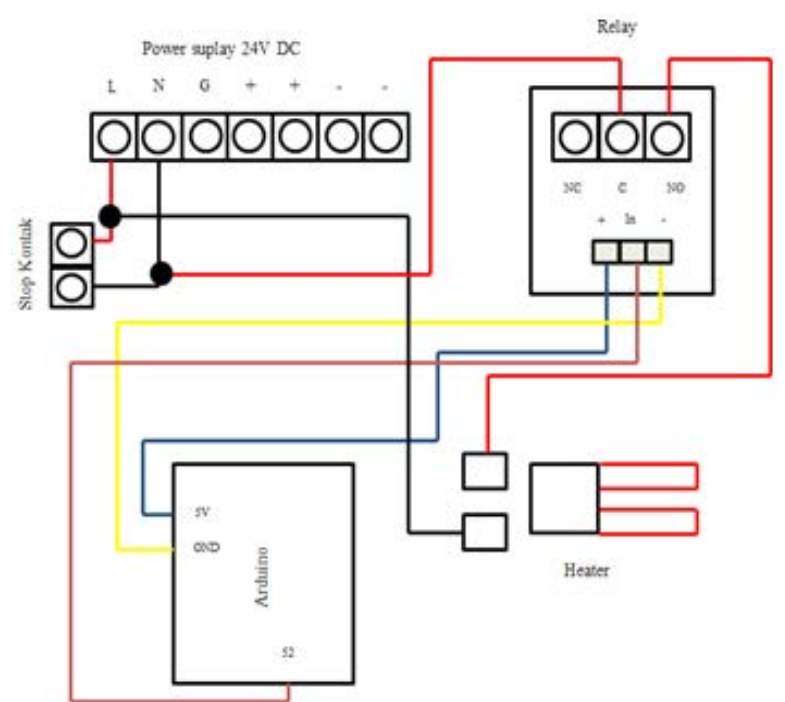

Gambar 7. Perancangan heater dari arduino 


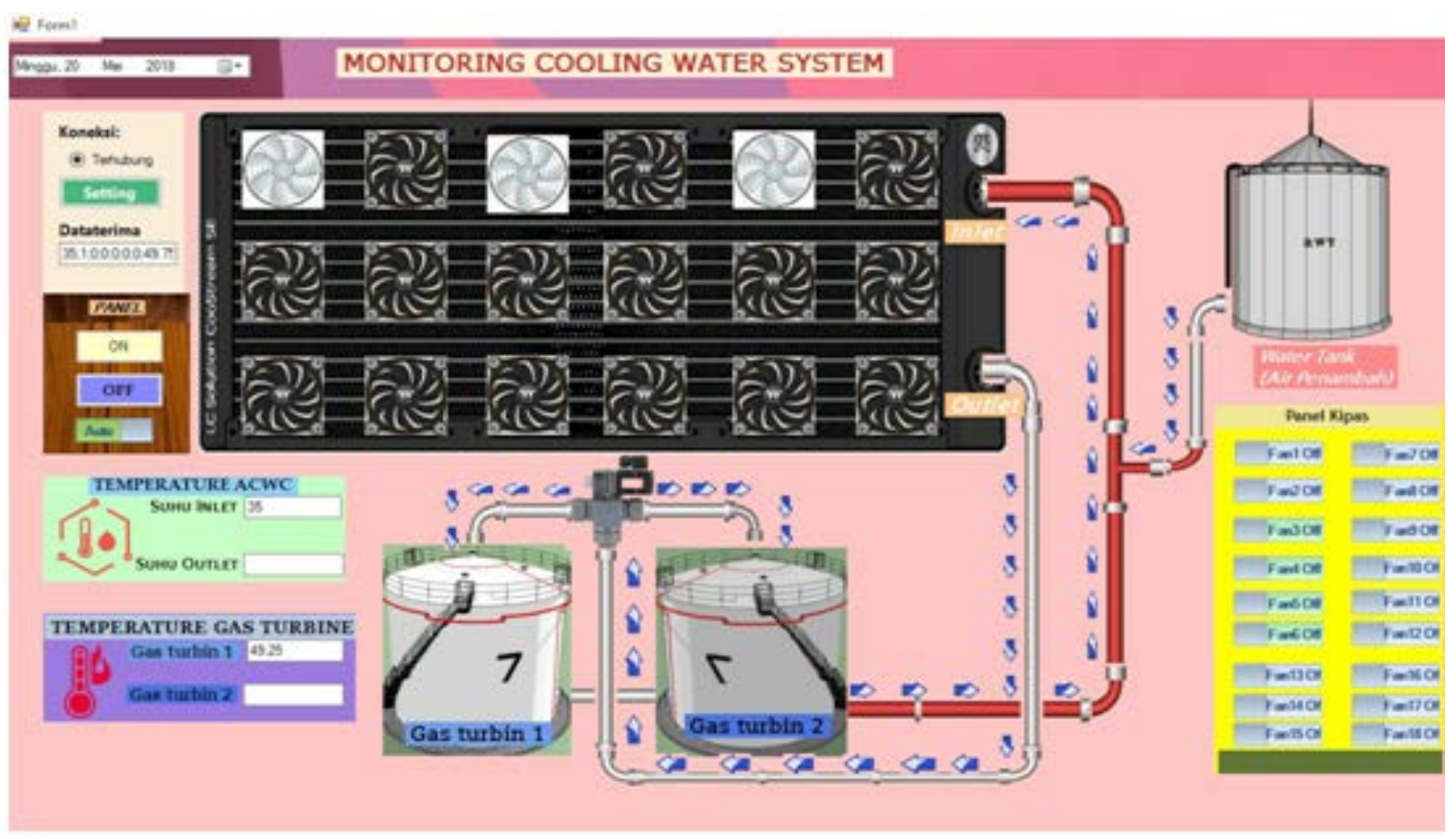

Gambar 8. Perancangan HMI

\section{HASIL DAN PEMBAHASAN}

Pada penelitian ini, hasil pembuatan masing-masing komponen dilakukan untuk mengetahui kemampuannya dalam mengatasi permasalahan yang diusulkan. Pembuatan dan pengujian dari sistem ini meliputi: pembuatan dan pengujian sensor thermocouple k Max6675 dengan arduino, pembuatan dan pengujian pompa air dengan driver L298N, pembuatan dan pengujian kipas berdasarkan suhu inlet.

\section{Pembuatan dan Pengujian Sensor Thermo- couple}

Setelah perancangan, dilakukan pembuatan dan pengujian kemampuan sensor dalam mendeteksi suhu. Tujuan dari pengujian ini adalah untuk mengetahui keakuratan dari sensor suhu yang digunakan pada penelitian ini. Keakuratan sensor tersebut, dapat menentukan berhasil tidaknya penelitian ini. Karena hasil keluaran dari sistem CWS ini dapat dipertanggung jawabkan.

Gambar 9 adalah hasil antarmuka sensor thermocouple ke arduino. Dengan menggunakan perangkat tersebut, kemudian data suhu hasil pembacaan thermocouple dibandingkan dengan alat ukur termometer digital untuk mengetahui besar error yang dihasilkan. Dari selisih persen kesalahan tersebut dapat diketahui, apakah sensor tersebut baik atau tidak? Atau apakah hasil pembacaan sensor tersebut perlu dikalibrasi atau tidak?. Hasil dari pengujian sensor thermocouple ini seperti ditunjukkan pada tabel 1 .

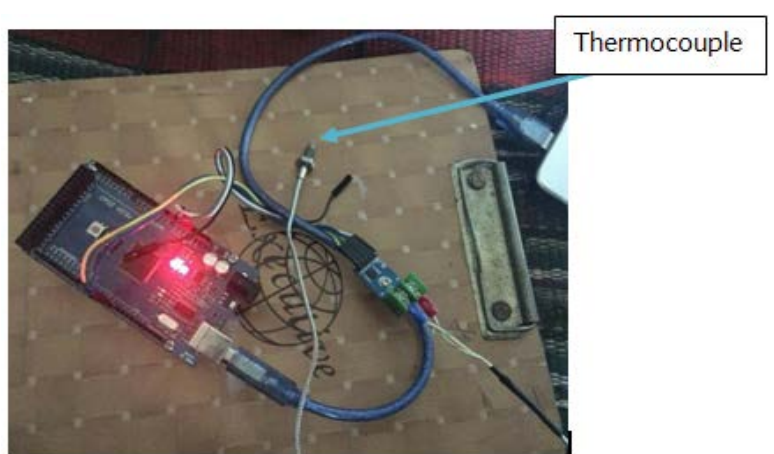

Gambar 9. Antarmuka sensor thermocouple ke arduino

Tabel 1. Perbandingan data sensor thermocouple dengan termometer

\begin{tabular}{cccc}
\hline $\begin{array}{c}\text { Pengujian } \\
\text { ke- }\end{array}$ & $\begin{array}{c}\text { Suhu pada } \\
\text { serial monitor } \\
\left({ }^{\circ} \mathrm{C}\right)\end{array}$ & $\begin{array}{c}\text { Suhu pada } \\
\text { alat ukur } \\
\left({ }^{\circ} \mathrm{C}\right)\end{array}$ & Error (\%) \\
\hline 1 & 29.25 & 29.04 & 0.7 \\
2 & 32.00 & 31.80 & 0.62 \\
3 & 35.00 & 34.80 & 0.57 \\
4 & 37.25 & 37.10 & 0.4 \\
5 & 40.05 & 39.60 & 1,12 \\
6 & 45.50 & 45.40 & 0.21 \\
7 & 52.25 & 52.00 & 0.47 \\
8 & 55.00 & 54.80 & 0.36 \\
9 & 62.00 & 62.09 & 0.14 \\
10 & 73.75 & 73.20 & 0.74 \\
& Rata-rata error & & 0,53 \\
\hline
\end{tabular}


Dari tabel 1 dapat disimpulkan bahwa sensor thermocouple memiliki error berkisar 0,53\% sehingga sensor tersebut merupakan sensor suhu yang cukup akurat untuk mewakili nilai suhu pada sistem.

\section{Pembuatan dan Pengujian Pompa Air}

Setelah perancangan, dilakukan pembuatan dan pengujian kemampuan pompa air 12 volt. Pompa ini disambungkan dengan driver L298N agar dapat mengatur kecepatan atau daya hisap pompa. Gambar 10 adalah rangkaian arduino, driver L298N dengan pompa dan gambar 11 adalah hasil pembuatan dan pengujian pompa. Keluaran dari arduino mengirimkan sinyal kepada driver, keluaran driver mengaktifkan pompa untuk menyalurkan air dari water tank dan mensirkulasikan dari turbin menuju CWS.

Dari gambar 11 dapat dijelaskan bahwa ketika pwm motor bernilai 45 maka tegangan ke motor adalah 3,05 volt dan ketika pwm bernilai 100 maka tegangan ke motor adalah 4,7 volt. Semakin besar nilai pwm maka semakin besar tegangan yang dikeluarkan. Pwm adalah pulse width modulation, di dalam pemrograman arduino, peneliti menggunakan 8 bit dalam pengoperasian sinyalnya.

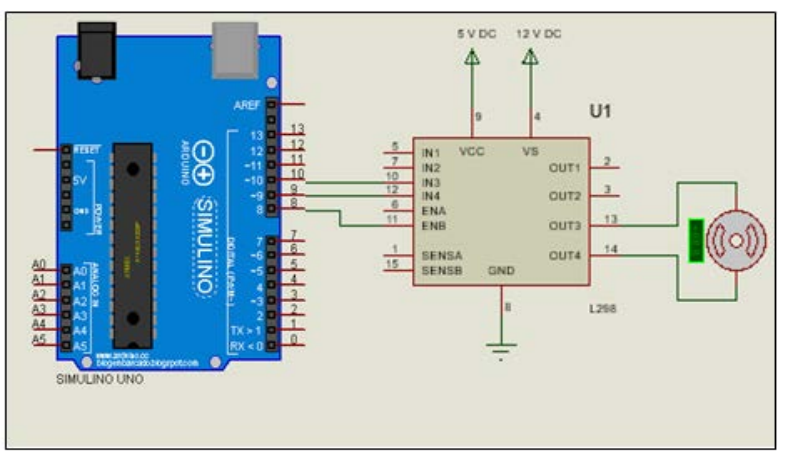

Gambar 10. Rangkaian arduino, driver dengan pompa

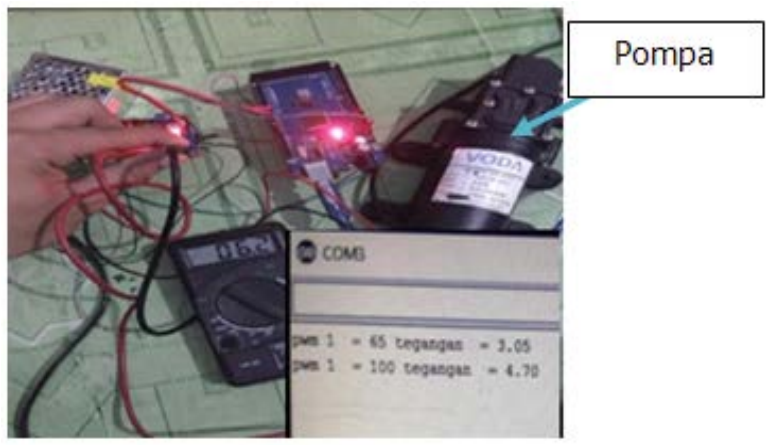

Gambar 11. Hasil pembuatan dan pengujian pompac. Pembuatan, Pengujian Kipas, dan Pengendalian Berbasis Level Suhu
Setelah perancangan, dilakukan pembuatan dan pengujian kemampuan kipas pendingin pada CWS. Pengoperasian kipas dapat dilakukan dengan mode manual dan otomatis. mode manual dilakukan melalui HMI dan mode otomatis berdasarkan pembacaan suhu inlet CWS dan pengendalian kipas berbasis level suhu di dalam program arduino. Gambar 12 dan Gambar 13 adalah hasil pembuatan kipas.

Hasil eksperimen dilakukan pada jumlah kipas yang aktif sesuai algoritma program terhadap suhu pada CWS, t ke SP dan daya kipas/jam dan daya kipas sesuai $t$ ke SP.

Dimana $P$ per jam adalah daya kipas per jam $(W), n$ adalah jumlah kipas, $V$ adalah tegangan kipas (V), I adalah arus kipas (ampere). Nilai $\mathrm{V}$ adalah $24 \mathrm{~V}$ dan I adalah 0,07 A.

Dimana t ke SP dalam satuan sekon dan 3600 memiliki satuan sekon.

Eksperimen dilakukan dengan suhu pada CWS adalah $35^{\circ} \mathrm{C}$ sampai $60^{\circ} \mathrm{C}$. Hasil eksperimen ditunjukkan pada tabel 2.

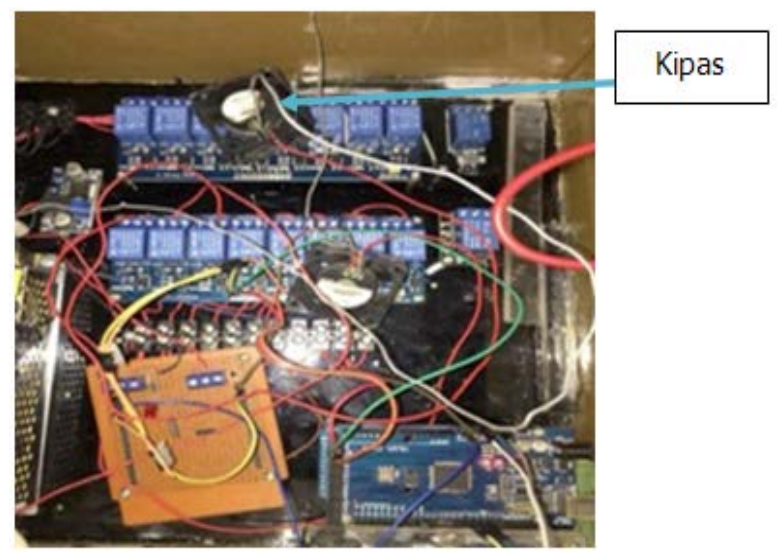

Gambar 12. Hasil pembuatan kipas

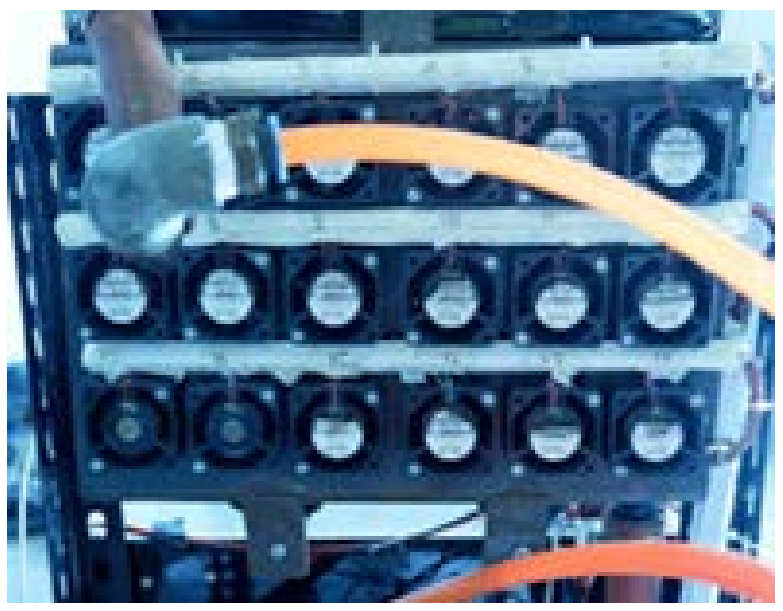

Gambar 13. Hasil pembuatan kipas pada cubing radiator $\mathrm{CW}$ 
42 | Munadhif, I., dkk, Pengendalian Otomatis Cooling Water System ...

Tabel 2. Hasil eksperimen pengendalian pada CWS

\begin{tabular}{|c|c|c|c|c|c|}
\hline No. & $\begin{array}{c}\text { Suhu } \\
\text { inlet } \\
\left({ }^{\circ} \mathrm{C}\right)\end{array}$ & $\begin{array}{c}\text { Jumlah } \\
\text { kipas } \\
\text { aktif }\end{array}$ & $\begin{array}{l}t \text { ke SP } \\
\text { (sekon) }\end{array}$ & $\begin{array}{l}\mathrm{P} / \mathrm{jam} \\
(\mathrm{W})\end{array}$ & $\begin{array}{l}\text { P sesuai t ke } \\
\text { SP (W) }\end{array}$ \\
\hline 1 & 35 & 0 & 0 & 0 & 0 \\
\hline 2 & 36 & 1 & 50 & 1.68 & 0.023333333 \\
\hline 3 & 37 & 2 & 88 & 3.36 & 0.082133333 \\
\hline 4 & 38 & 3 & 102 & 5.04 & 0.1428 \\
\hline 5 & 39 & 4 & 121 & 6.72 & 0.225866667 \\
\hline 6 & 40 & 5 & 146 & 8.4 & 0.340666667 \\
\hline 7 & 41 & 6 & 173 & 10.08 & 0.4844 \\
\hline 8 & 42 & 7 & 204 & 11.76 & 0.6664 \\
\hline 9 & 43 & 8 & 267 & 13.44 & 0.9968 \\
\hline 10 & 44 & 9 & 378 & 15.12 & 1.5876 \\
\hline 11 & 45 & 10 & 495 & 16.8 & 2.31 \\
\hline 12 & 46 & 11 & 546 & 18.48 & 2.8028 \\
\hline 13 & 47 & 12 & 623 & 20.16 & 3.4888 \\
\hline 14 & 48 & 13 & 688 & 21.84 & 4.173866667 \\
\hline 15 & 49 & 14 & 704 & 23.52 & 4.599466667 \\
\hline 16 & 50 & 15 & 756 & 25.2 & 5.292 \\
\hline 17 & 51 & 16 & 787 & 26.88 & 5.876266667 \\
\hline 18 & 52 & 17 & 805 & 28.56 & 6.386333333 \\
\hline 19 & 53 & 18 & 823 & 30.24 & 6.9132 \\
\hline 20 & 54 & 18 & 845 & 30.24 & 7.098 \\
\hline 21 & 55 & 18 & 866 & 30.24 & 7.2744 \\
\hline 22 & 56 & 18 & 900 & 30.24 & 7.56 \\
\hline 23 & 57 & 18 & 943 & 30.24 & 7.9212 \\
\hline 24 & 58 & 18 & 978 & 30.24 & 8.2152 \\
\hline 25 & 59 & 18 & 1023 & 30.24 & 8.5932 \\
\hline 26 & 60 & 18 & 1050 & 30.24 & 8.82 \\
\hline
\end{tabular}

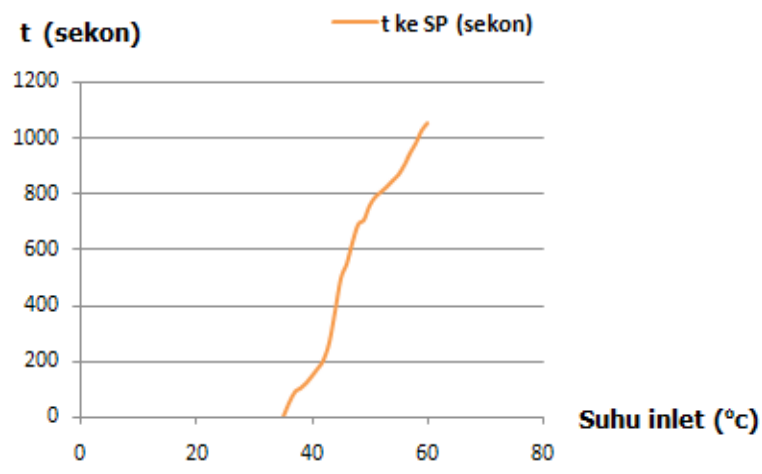

Gambar 14. Grafik t ke SP terhadap suhu inlet

Dari tabel 2 dapat dijelaskan bahwa semakin tinggi suhu inlet, maka semakin lama t ke SP dan semakin besar daya kipas sesuai t ke SP yang dipakai untuk menstabilkan sistem. Namun saat suhu inlet di atas $53^{\circ} \mathrm{C}$, daya kipas setiap jam cenderung konstan dan waktu yang diperlukan untuk mendinginkan sistem menjadi lebih lama.

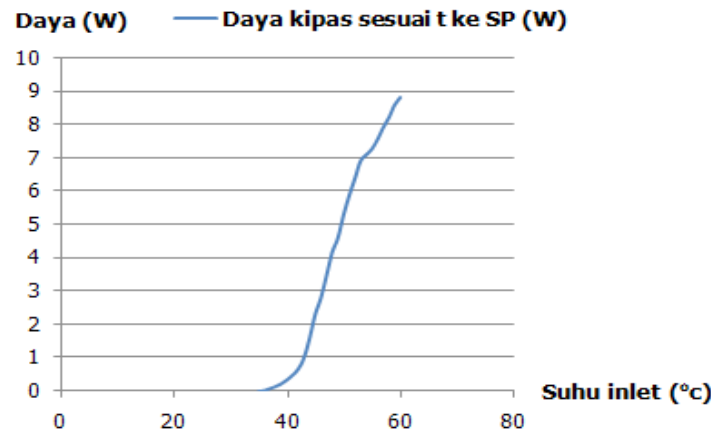

Gambar 15. Grafik daya kipas sesuai t ke SP terhadap suhu inlet

\section{KESIMPULAN}

Pengendalian CWS pada pendingin gas turbin berdasarkan masukan suhu inlet dan keluaran berupa 18 kipas 24 Volt DC, heater, dan pompa telah berhasil dilakukan. Pengujian dilakukan pada kemampuan sensor thermocouple yang memiliki error sebesar $0,53 \%$ dari termometer. Pengujian pompa yang semakin besar pwm diberikan maka semakin besar daya hisapnya. Pengujian heater yang aktif karena relay on saat sistem diaktifkan. Pengujian kipas berdasarkan masukan suhu dan pengendali CWS berbasis level suhu disimpulkan bahwa semakin tinggi suhu inlet, maka semakin lama $t$ ke SP dan semakin besar daya kipas sesuai $t$ ke SP yang dipakai untuk menstabilkan sistem.

\section{DAFTAR PUSTAKA}

Sumarno, G. (2015). Perpindahan Panas pada Gas Turbine Closed Cooling Water Heat. Jurnal Teknik Energi.1(1): 85-86.

Turang, D. A. O. (2015). Pengembangan Sistem Relay Pengendalian Dan Penghematan Pemakaian Lampu Berbasis Mobile. Seminar Nasional Informatika 2015 UPN Veteran Yogyakarta (p. 78)

Alam, H. S., Sasso, J., \& Djunaedi, I. (2016). An Illustration of Thermodynamic Modeling and Economic Analysus of Inlet Air Chilling System for Gas Turbine Power Augmentation.

Incropera, F. P., Dewitt, D. P., Bergman, T. L., \& Lavine, A. S. (2007). Fundamentals of Heat and Mass Transfer (6th ed.). Asia: John Wiley \& Sons

Handoyo, E. A. (2000). Pengaruh Kecepatan Aliran Terhadap Efektivitas Shell and Tube Heat exchanger. Jurnal Teknik Mesin. II (2) : 86-90.

Gas Power Systems. (2011). In M. J. Moran, H. N. Shapiro, D. D. Boettner, \& M.B. Bailey, Fundamentals of Engineering Thermodynamics (pp. 509-520). United States of America: John Wiley \& Sons, Inc.

Boyce, M. P. (2002). Gas Turbine Engineering Handbook. Texas: Houston. 